\title{
Serological, clinical and histopathological changes in naturally infected dogs with Leishmania infantum in the khemisset province, Morocco
}

\author{
Amale NATAMI ${ }^{\mathrm{a}}$, Hamid SAHIBI ${ }^{\mathrm{b} *}$, Sâadia LASRI ${ }^{\mathrm{b}}$, \\ Mohammed Boudouma $^{\mathrm{a}}$, Nouzha Guessouss-IDRRISSI ${ }^{\mathrm{c}}$, \\ Abdelkébir RHALEM ${ }^{\mathrm{b}}$

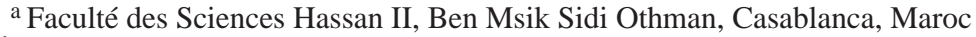 \\ ${ }^{\mathrm{b}}$ Département de Parasitologie et Maladies Parasitaires, Institut Agronomique \\ et Vétérinaire Hassan II, Rabat, Maroc \\ ${ }^{c}$ Laboratoire de Parasitologie, Unité de Recherche sur les Leishmanioses, Faculté de Médecine, \\ Casablanca, Maroc
}

(Received 5 August 1999; accepted 17 January 2000)

\begin{abstract}
Canine leishmaniasis (canL) is widespread in the north of Morocco and the Leishmania infantum local strains are highly virulent. An epidemiological survey was carried out in 1993-1995 in the Khemisset province. In this region, the severity of the disease was assessed during regular visits to the identified foci by clinical examination of 323 dogs. Clinical signs were protean and occurred in various combinations. Biopsies were made on available sick dogs; the main histological changes were severe infiltration of the spleen, lymph nodes and bone marrow by mononuclear cells and hyperplasia of macrophage cells with amastigotes in their cytoplasm. The seroprevalence among $323 \mathrm{dog}$ sera tested by ELISA showed a rate of $16.71 \%$. The highest prevalence of the disease was $23.6 \%$ in the Sid El Ghandour hamlet. A comparison of the results of this study with those from the year following the first examination on the same site (Sid El Ghandour) of 67 dogs showed that the disease prevalence had not increased significantly ( $23.6 \%$ to $25.33 \%)$.
\end{abstract}

dog / Leishmania infantum / histopathology / seroprevalence / Morocco

Résumé - La leishmaniose canine : étude sérologique, clinique et histopathologique dans la province de Khemisset, Maroc. La leishmaniose canine (L.can) est largement répandue dans la partie Nord du Maroc et les souches de Leishmania infantum sont très virulentes. Dans la présente étude, nous rapportons les résultats d'une enquête sur la leishmaniose canine au Maroc dans la province de Khemisset de 1993 à 1995. La gravité de la maladie a été évaluée par l'examen clinique minutieux de

* Correspondence and reprints

Tel.: (212) 76804 24; fax: (212) $7680424 / 778135$ 
323 chiens lors de visites régulières dans les foyers identifiés. Les signes cliniques ont révélé un caractère protéiforme et un manque de constance des symptômes. Les biopsies des ganglions, rate et moelle osseuse ont montré une infiltration massive par les cellules mononucléaires et une hyperplasie de macrophages avec des amastigotes dans leur cytoplasme. La recherche des anticorps antiLeishmania effectuée par la technique ELISA a révélé une séro-prévalence moyenne de 16,71\% avec 23,63\% dans la localité de Sid El Ghandour seule. La comparaison des résultats de cette étude avec ceux d'une année après la première visite dans cette dernière localité sur 67 chiens a montré que la prévalence n'a pas augmenté significativement $(23,6 \%$ à $25,33 \%)$.

chien / Leishmania infantum / histopathologie / séroprévalence / Maroc

\section{INTRODUCTION}

Visceral leishmaniasis is a severe disease primarily of humans and canine caused by infection with protozoa belonging to the genus Leishmania [15]. In humans, symptoms of the disease include fever, spleen and liver enlargement, immunosuppression and weight loss [1]. However, in dogs, symptoms are protean and occur in various combinations [17]. In the Mediterranean area, canine leishmaniasis is caused by Leishmania infantum, an intracellular protozoa living in the mononuclear phagocyte system. The incidence of canine infection can be as high as $40 \%$ in endemic areas [8]. Dogs are the domestic reservoir of Mediterranean visceral leishmaniasis and are important in zoonotic transmission $[6,14]$.

In Morocco, natural canine leishmaniasis was first reported by Jeaume in 1932 [10]. Few epidemiological data are, however, available concerning its epidemiology and clinical features. Before 1995, human visceral leishmaniasis was not an obligatory declared disease. Recently, the Ministry of Health notified one human visceral leishmaniasis case in the Khemisset province in 1996-1997 [7].

The purpose of this study was to perform a survey on canine leishmaniasis designed to provide data on the prevalence of the disease, its clinical and parasitological features, and the histopathology in naturally infected dogs in six localities of the Khemisset province in 1993-1994. The evolution of the disease during the year following the first examination was also studied in Sid El Ghandour in order to follow the evolution of the disease in this locality.

\section{MATERIALS AND METHODS}

\subsection{Site of study}

Khemisset lies in north-western Morocco, $80 \mathrm{~km}$ from Rabat. Its territory covers an area of 850000 ha reaching $145 \mathrm{~m}$ above sea level.

The average annual rainfall is $700 \mathrm{~mm}$ and the temperature varies between $5{ }^{\circ} \mathrm{C}$ (January) and $37^{\circ} \mathrm{C}$ (June). The total canine population was estimated to be about 120000.

This study was carried out from August 1993 to February 1994 in the Sid El Ghandour hamlet (around a canine leishmaniasis case) and five other rural localities (Jbel, Tafoudait, Aït Iskou Hirra, Aït Azzouz ou Ali and Fouaïzen Aït Abbou) belonging to the Khemisset province. Sid El Ghandour is a swampy valley, $1 \mathrm{~km}$ from Khemisset city where farmers use wastewater for irrigation. The average number of local dogs per house varies between 2 and 3, which are frequently chained overnight in the field to guard the produce. In order to study the evolution of the disease during the year following the first examination (from December 1994 to August 1995), another study was carried out in the Sid El Ghandour locality on all notified seropositive and seronegative dogs and pups who were examined at regular visits. 


\subsection{Sampling}

A total of 323 dogs were identified from August 1993 to February 1994 by their owners and their blood was sampled. During the period from December 1994 to August 1995, a total of 67 dogs (42 seronegative dogs from the previous year, 17 newborn dogs and 8 new introduced cases) existing in the Sid El Ghandour hamlet was sampled and clinically examined. The seroprevalence was calculated as follow:

seropositives from the previous year + recent seropositives / total number of dogs in this hamlet.

\subsection{Clinical and parasitological examination}

A total of 323 dogs were examined for signs of the disease, including popliteal lymph node size, onychogryphosis, depilation, ulceration and weight loss. Six sick dogs were hospitalised in our veterinary hospital and the course of the infection was followed. Parasitological exams were carried out on the 6 dogs on popliteal lymph node tissues and spleen biopsies guided by echography. Part of the material obtained was smeared on slides for Giemsa staining [12]. Other parts were inoculated on NNN medium for parasite isolation. The same procedure was done for the $67 \mathrm{dogs}$ of Sid El Ghandour after one year.

Four strains were isolated from only 4 of these 6 dogs and were typed by the Unit of Research on Leishmaniasis, Laboratory of Parasitology and Mycology of the Faculty of Medicine, Casablanca (Morocco), by multilocus enzyme electrophoresis (10 loci) on cellulose acetate [11].

\subsection{Histopathological analysis}

In order to determine the pathogenesis of the isolated strains, samples of lymphoid tissues (bone marrow, liver, lungs, spleen and popliteal lymph nodes) were taken from 3 of the 6 dogs and were fixed in $10 \%$ neutral formalin. Tissue blocks were embedded in paraffin and sectioned to 5- $\mu$ m thickness. Slides were stained with Hematoxylin and Eosin.

\subsection{ELISA test}

Assessment of seropositivity on 323 sera (1993-1994) and on 67 sera (1994-1995) was carried out by ELISA using promastigotes from a local Leishmania infantum (LRG) strain, isolated from a sick dog from the Sid El Ghandour hamlet, whose isoenzyme pattern is indistinguishable from the WHO reference strain MHOM/TN/80/IPT1 zymodeme MON-1. This test was a modification of a procedure reported for use in humans by Voller et al. [18]. Promastigotes were washed 3 times in PBS, sonicated and then adjusted to $100 \mu \mathrm{g} \cdot \mathrm{mL}^{-1}$ in $0.05 \mathrm{M}$ carbonate-bicarbonate buffer, $\mathrm{pH}$ 9.6. The protein content of the antigens was determined by the method of Bradford [4]. This preparation was then adsorbed on plates (Dynatech Immulon) and allowed to adhere overnight at $4{ }^{\circ} \mathrm{C}$. The plates were blocked for $2 \mathrm{~h}$ in PBS / BSA $2 \%$, washed 3 times in PBS / Tween $0.05 \%$ and stored at $-30{ }^{\circ} \mathrm{C}$. The plates were incubated with $100 \mu \mathrm{L}$ of diluted serum $(1 / 100$ in PBS) at $37^{\circ} \mathrm{C}$ for $1 \mathrm{~h}$, then the wells were washed 3 times. The conjugate (Peroxidase - Protein A) was diluted to 1/8000 in PBS and $100 \mu \mathrm{L}$ were added to each well. The plates were incubated for $1 \mathrm{~h}$ at $37^{\circ} \mathrm{C}$, and then washed 3 times. $100 \mu \mathrm{L}$ per well of substrate 2,2'-azino-bis (3-ethylbenzthiazoline sulfonate) (ABTS) was used and the absorbance was read at $405 \mathrm{~nm}$ after $20 \mathrm{~min}$. Positive and negative controls were used in each experiment. Positive values were defined as those whose optical densities (OD) were $>0.3$. 


\subsection{Statistical analysis}

Data were analysed by the Chi-Square $\left(\chi^{2}\right)$ test.

\section{RESULTS}

Our investigations concerning the 323 dogs allowed us to release some facts about the Khemisset province and the identified focus: $90 \%$ of the surveyed dogs were not subject to veterinary control, $10 \%$ of the dogs were stray, $60 \%$ not chained and $30 \%$ chained compared to $4 \%$ stray, $10 \%$ half-stray and $86 \%$ chained in the Sid El Ghandour locality.

\subsection{Clinical and parasitological results}

Among the 323 dogs examined in the 6 defined localities of Khemisset, 35 $(10.83 \%)$ dogs showed clinical signs (Tab. I). Only 6 dogs presented severe signs of the disease. These 6 dogs were parasitologically confirmed by Giemsa staining. Four Leishmania isolates ( 2 cultures were lost) were obtained from 4 of these dogs and all were typed as Leishmania infantum. In the Khemisset province, dogs clinically suspected exhibited certain signs like generalised onychogryphosis and peripheral lymphadenopathy (Tab. II). Weight-loss, muscular atrophy and hepatosplenomegaly were also seen. Skin lesions included dermatitis, alopecia, dandruff production and ulcers. The 4 dogs from which strains were isolated and typed, presented the symptoms summarised in Table III.

\subsection{Histopathological changes in naturally infected dogs}

The 3 dogs studied for histopathology showed histologically identified lesions. The lymph nodes and spleen of these 3 infected dogs were markedly enlarged and presented severe infiltration by mononuclear cells with a high number of amastigotes in the cytoplasm (Fig. 1 and 2). The 3 infected dogs had changes in bone marrow consisting of a slight increase in the number of macrophages, which were found to contain Leishmania spp. (Fig. 3). It was easier to detect amastigotes in the spleen than in the lymph nodes.

\subsection{Serology}

From the 323 dogs, 54 were found to be ELISA positive (Tab. I). Six (11.11\%) of these 54 dogs were parasitologically confirmed for visceral leishmaniasis. All ELISA positive sera had OD values higher than 0.3 , while all sera from healthy controls had

Table I. Percentages of dogs clinically suspected, parasitologically confirmed and seropositive (1993-1994).

\begin{tabular}{lccc}
\hline Localities & $\begin{array}{c}\text { Dogs clinically } \\
\text { Suspected }(\%)\end{array}$ & $\begin{array}{c}\text { Cases confirmed } \\
\text { by finding parasites }(\%)\end{array}$ & $\begin{array}{c}\text { ELISA positive } \\
\text { dogs }(\%)\end{array}$ \\
\hline Jbel & $8 / 65(12.3)$ & $\mathrm{ND}$ & $13 / 65(20)$ \\
Tafoudaït & $7 / 70(10)$ & $\mathrm{ND}$ & $11 / 70(15.71)$ \\
Aït Iskou Hirra & $9 / 62(14.51)$ & $\mathrm{ND}$ & $9 / 62(14.51)$ \\
Aït Azzouz ou ali & $2 / 35(5.71)$ & $\mathrm{ND}$ & $8 / 35(22.85)$ \\
Fouaïzen aït Abbou & $0 / 36(0)$ & $6 / 55(10.9)$ & $0 / 36(0)$ \\
Sid El Ghandour & $9 / 55(16.36)$ & $6 / 323(1.85)$ & $13 / 55(23.63)$ \\
Total & $35 / 323(10.83)$ & & $54 / 323(16.71)$ \\
\hline
\end{tabular}


Table II. Clinical signs presented by the 35 suspected dogs.

\begin{tabular}{lc}
\hline Clinical signs & Frequency $(\%)$ \\
\hline *General status & \\
- suffering from weight-loss & $33(94.28)$ \\
- illness & $15(42.85)$ \\
- emaciation & $17(48.57)$ \\
*Skin lesions & \\
- alopecia & $8(22.85)$ \\
- dermatitis & $15(42.85)$ \\
- dandruff production & $14(40)$ \\
- ulcers & $8(22.85)$ \\
*Onychogryphosis & $35(100)$ \\
*Ocular lesions & $15(42.85)$ \\
- conjunctivitis & $7(20)$ \\
- blue keratitis & $7(20)$ \\
- blindness & \\
*Digestive signs & $2(5.71)$ \\
- diarrhoea & \\
*Visceral signs & \\
- lymphadenopathy & $35(100)$ \\
- spleno and hepatomegaly & $6(17.14)$ \\
*Nervous signs & \\
- paralysis of rear limbs & $1(2.85)$ \\
\hline
\end{tabular}

values less than 0.3. Amongst the 54 ELISA positive dogs, $35(64.81 \%)$ were symptomatic and $19(35.18 \%)$ were asymptomatic. We also noted that in the Sid El Ghandour locality alone 13 seropositive cases were found and a $23.6 \%$ seroprevalence was reached.

\subsection{Evolution of the disease in the Sid El Ghandour locality during one year}

Reliable data on the evolution of the disease could be obtained for $67 \mathrm{dogs}$ in the Sid El Ghandour locality where we continued our serosurvey for one year. Among the 13 seropositive dogs, 5 were sick, 4 died of severe leishmaniasis by the end of December 1994 and the fifth one died in June 1995. During the period from December 1994 to August 1995, a total of 67 dogs existing in the focus area were tested by ELISA at a $1 / 100$ dilution. The results showed how the disease was evolving in this focus area. Among the 67 dogs examined, 7 presented clinical signs and 11 were seropositive (recent infections). The parasitological examination was negative. All of these 11 dogs were previously diagnosed as being seronegative in 1993-1994.

After one year from the first examination, the seroprevalence had not increased significantly in Sid El Ghandour: 23.6\% in 1993-1994 and $25.33 \%$ in 1994-1995 (11 recent infections plus 8 infections from the previous year $/ 67+8)$.

Table III. Symptoms presented by 4 dogs from which strains were isolated and typed in the province of Khemisset.

\begin{tabular}{lcccc}
\hline & \multicolumn{4}{c}{ Strains of L. infantum } \\
Symptoms & Kh1 & Kh4 & Kh5 & Kh6 \\
\hline Weight-loss & + & + & + & + \\
Onychogryphosis & + & + & + & + \\
Conjunctivitis & + & + & - & - \\
Dandruff production & + & + & - & - \\
Emaciation & + & + & + & + \\
Lymphadenopathy & + & + & + & - \\
Spleno and hepatomegaly & + & + & - & - \\
Nervous signs & - & & & - \\
\hline
\end{tabular}




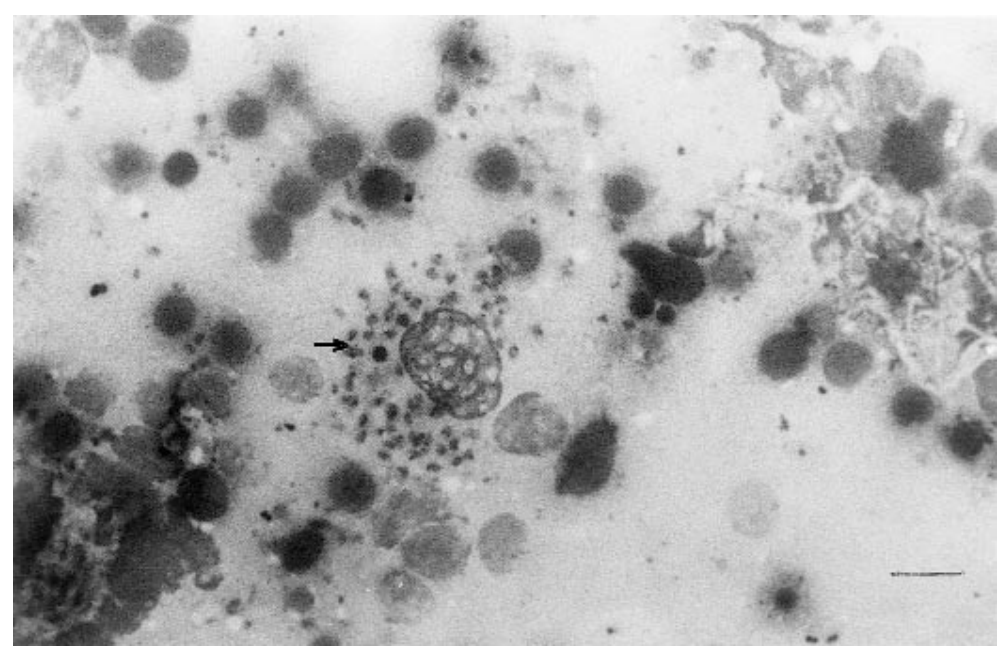

Figure 1. Photomicrograph of lymph node section showing macrophages with amastigotes (arrows). $($ Hematoxylin and Eosin, bar $=10 \mu \mathrm{m})$.

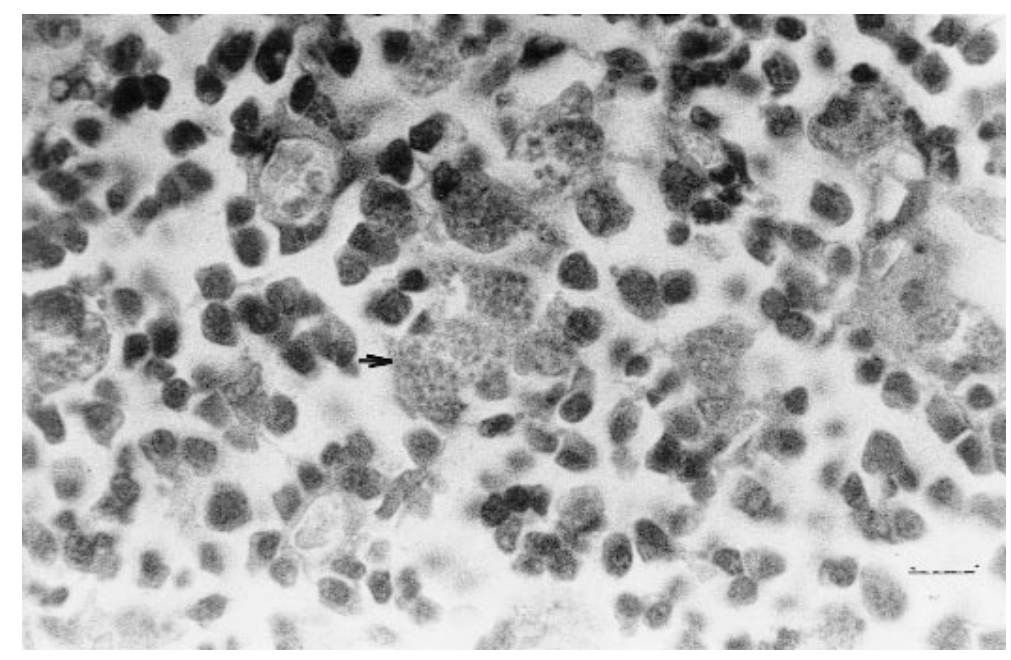

Figure 2. Photomicrograph of spleen section. Splenic granulomas with heavily parasitised macrophages (arrows). (Hematoxylin and Eosin, bar $=10 \mu \mathrm{m}$ ).

\section{DISCUSSION}

Our results were obtained by clinical, histopathological and serological data. Clinical records included a large variability of signs including visceral and cutaneous changes. On clinical grounds, canine leishmaniasis was suspected in cases of emaciation, peripheral lymphadenopathy, onychogryphosis, dermatitis and kerato- 


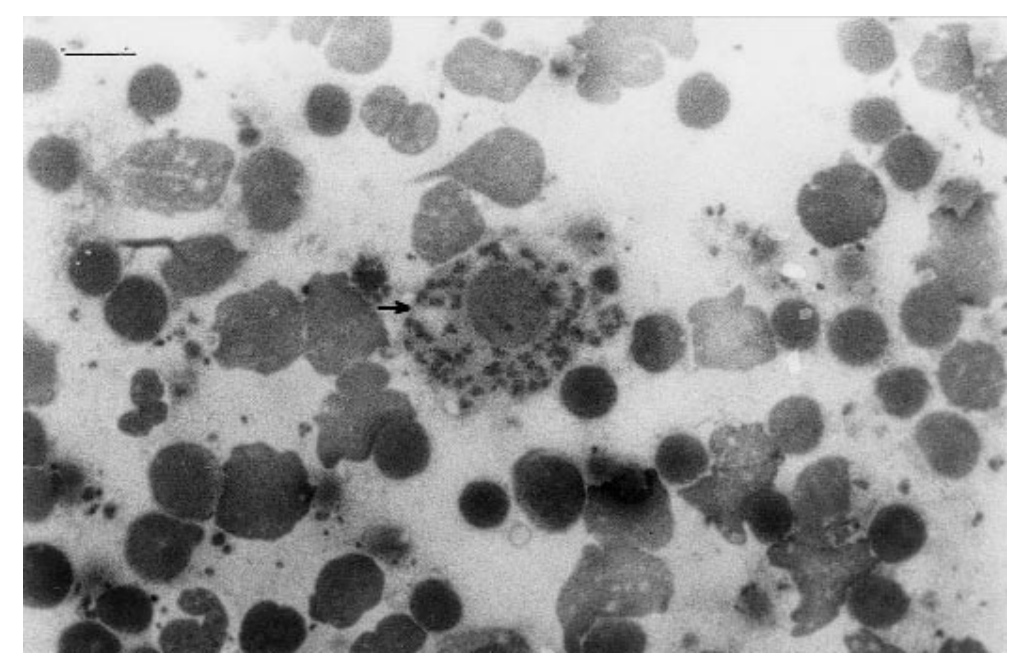

Figure 3. Photomicrograph of bone marrow demonstrating amastigotes inside macrophages (arrows). $($ Hematoxylin and Eosin stain, bar $=10 \mu \mathrm{m})$.

conjunctivitis. In our study, 35 of the 323 dogs $(10.83 \%)$ were clinically suspected. The majority of Leishmania-infantuminfected dogs in Jbel, Tafoudaït, Aït Iskou, Aït Azzouz ou Ali and Sid El Ghandour showed signs similar to those previously observed in other endemic areas [17]. Parasitological tests were performed on the dogs to corroborate the clinical diagnoses. The presence of the parasite was confirmed by smears from lymph nodes and spleen imprints. Parasites were found in tissue biopsies from only $11.11 \%$ of the dogs with positive ELISA titres. This was explained by the long incubation time of this disease [1, 2]. It is known that the majority of dogs do not exhibit clinical signs because parasites have a long incubation period before invasion of tissues of the organism $[1,2]$. The basic lesions involved proliferation and parasitisation of macrophages with the most striking lesions observed in the spleen, bone marrow and lymph nodes. The predominant histopathological lesions were hyperplasia of macrophages with a high number of amastigotes in the cytoplasm of cells in the tissues. Similar findings were obtained by Vassilios et al. [17]. In our study the ELISA technique revealed $35.18 \%$ of prepatent cases, which did not develop signs of the disease and $64.81 \%$ of symptomatics. The ELISA data showed the existence of zones with prevalences equal to zero (Fouaïzen Ait Abou), zones with mean prevalences varying from 14 to $20 \%$ (Jbel, Tafoudait, Ait Iskou), and zones with prevalences higher than 20\% (Aït Azzouz ou Ali and Sid El Ghandour). This discrepancy might be explained by the socio-economical particularities of each locality. In Sid El Ghandour, $86 \%$ of the dogs are chained to guard produce, and are therefore more accessible to phlebotomies. This locality was found to be highly endemic and the seroprevalence in local dogs in 1993-1994 was $23.6 \%$ compared to the figures reported in the Mediterranean area: $6.2 \%$ in Tunisia [5], 37\% in Sicily, Italy [14]; $12 \%$ in the north of France [9] and 22.5\% in Canea Creta, Greece [19]. Recent clinical and serological findings added to the results of an entomological study done by the Unit of Research on 
Leishmaniasis, Laboratory of Parasitology, Faculty of Medicine Casablanca, Morocco (unpublished data) have provided strong evidence that Sid El Ghandour represents a focus of leishmaniasis. No human visceral leishmaniasis case was, however, reported in this locality during the whole study period which suggests that it is a specific CanL focus.

The absence of human leishmaniasis in Khemisset instead of a high prevalence of canine leishmaniasis should not be surprising. There are several consistent canine leishmaniasis foci where no human VL cases have been reported (for example in Italy, Monte Argentario (Tuscany) and in the island of Ustica (Sicily) cited by Bettini and Gradoni, [3]. There was no history of foreign travel by any of the dogs examined. This suggests that the disease is endemic.

In the Sid El Ghandour region during the year after the first examination, $5(38.4 \%)$ of the dogs with clinical signs died of the disease in late December 1994. This was explained by the immunological status of these dogs who were immunosuppressed and also indicates that the local strains are highly virulent. This late data was confirmed by experimental infection under controlled conditions by Rhalem et al. [16]. We also noticed a seroconversion of 11 dogs already diagnosed as being seronegative before the activity of sandflies. These results showed that Sid El Ghandour is a highly endemic focus of CanL, characterised by a continuous and maintained activity of disease transmission. All our isolated strains showed an isoenzyme pattern identical to that of reference strains that cause human visceral leishmaniasis in the Mediterranean basin, defined as L. infantum [13].

In the Khemisset province, the animal reservoir of the disease is dogs. It is reported that the importance of canine leishmaniasis $(\mathrm{CanL})$ in this area could by itself insure the epidemiological cycle, maintain the disease and constitute an important epidemiological indicator of human visceral leishmania- sis. This study has not only encouraged research on canine leishmaniasis in Morocco, but has also allowed us to understand the social status of dogs in this region and to discover the localities exposed to a risk.

\section{ACKNOWLEDGMENTS}

This work was supported by the USAID/NIAID-NIH, USA project.

\section{REFERENCES}

[1] Abranches P., Silva Pereira M.C., Conceicao Silva F.M., Santos Gomes G.M., Janz J.G., Canine leishmaniasis: Pathological and ecological factors influencing transmission of infection. J. Parasitol. 77 (1991) 557-561.

[2] Ashford R.W., Bettini S., In the leishmaniasis in Biology and Medicine, in: W. Peters and KillickKendrick (Eds.), Ecology and epidemiology: New World., Academic Press, London, 1987, p. 365.

[3] Bettini S., Gradoni L., Canine leishmaniasis in the mediterranean area and its implications for human leishmaniasis, Insect Sci. Appl., 7 (1986) 241-245.

[4] Bradford M., A rapid and sensitive method for the quantitation of microgram quantities of protein utilizing the principle of protein-dye binding, Ann. Biochem. 72 (1976) 248-254.

[5] Dedet J., Ben Osman F., Chadli A., Croset H., Rioux J. A., La leishmaniose canine en Tunisie, Ann. Parasitol. Hum. Comp., 48 (1973) 653-660.

[6] Delmont J., Les leishmanioses, La gazette de l'étudiant, Gaz. Med. France 90 (1983) 2857-2868.

[7] Direction de l'Epidémiologie et de la Lutte contre les maladies, DMT, Service des Maladies Parasitaires, État d'avancement des programmes de lutte contre les maladies parasitaires, Rapport annuel d'activité, 1996-1997, Ministère de la santé publique, Maroc.

[8] Flemmings B.J., Papas M.G., Keenan C.M., Hochmeyer W., Immune complex decomplementation of canine sera for use in a complementfixation test for diagnosis of visceral leishmaniasis, Am. J. Trop. Med. Hyg. 33 (1984) 553-559.

[9] Guilhon J., Jolivet G., Marchand A., La leishmaniose canine autochtone dans la région Parisienne et dans l'Ouest de la France, Bull. Acad. Vét. (1986) 199-211.

[10] Jeaume G., Un cas de leishmaniose naturelle généralisée chez le chien au Maroc. Bull. Soc. Path. Exot. 25 (1932) 225-227. 
[11) Kreutzer R.D., Christensen H.A., Characterisation of leishmania spp. by isoenzyme electrophoresis. Am. J. Trop. Med. Hyg. 29 (1980) 199-208.

[12] Lanotte G., Rioux J.A., Croset H., Vollhardt Y., Ecologie des leishmanioses dans le sud de la France.7. Dépistage de l'enzootie canine par les méthodes immunosérologiques, Ann. Parasitol. Hum. Comp. 49 (1974) 41-62.

[13] Maazoun R., Lanotte G., Pasteur N., Rioux J.A., Kennon M.F., Pratlong F., Ecologie des leishmanioses dans le sud de la France. 16. Contribution à l'analyse chimiotaxonomique des parasites de la leishmaniose viscérale méditerranéenne. A propos de 55 souches isolées en Cévennes, Côte d'Azur Corse et Tunisie, Ann. Parasitol. Hum. Comp. 56 (1981) 131-146.

[14] Mansueto S.M., Celii M.D., Quatararo P., Counter immunoelectrophoresis (CIEP) and ELISA tests in the diagnosis of canine leishmaniasis, Ann. Trop. Med. Parasitol. 76 (1982) 229-231.

[15] Pinelli E., Killick-Kendrick R., Wagnaar J., Bernandina W., Deal G., Ruitenberg J., Cellular and Humoral Responses in Dogs Experimentally and Naturally Infected with Leishmania infantum, Infect. Immun. 178 (1994) 229-235.

[16] Rhalem A., Sahibi H., Guessous N., Lasri S., Natami A., Riyad M., Berrag B., Immune response against Leishmania antigens in dogs naturally and experimentally infected with Leishmania infantum, Vet. Parasitol. 81 (1999) 173184.

[17] Kontos V.J., Koutinas A.E., Old world canine leishmaniasis, Compend. Contin. Educ. Practicing Veterinarian 15 (1993), 949-960.

[18] Voller A., Bidwell D.E., Bartlett A., Enzyme Linked immunosorbent assay, in: Rose N., Friedman H. (Eds.), Manual of Clinical Immunology, American Society of Microbiology, Washington, DC, 1980, pp. 359-371.

[19] Zahar A.R., Studies on leishmaniasis vector/reservoirs and their control in the old world, Parts I, II, III, World Health Organisation/VBC/ 79, 19791980, pp. 749-776. 